\title{
Strategies and Problems of Pharmaceutical Industry Development in the Context of an Increased State Regulation
}

\author{
Ashikhina L.A.* Lisichkina N.V. Bolshakova L.S. Goloktionova Ju.G. Izvekova E.V. \\ Kuzina A.V. Ladnova O.L. Merkulova E.G.
}

Orel State University of Economics and Trade, Orel, Russia

*Corresponding author. Email: alla-orel@ya.ru

\begin{abstract}
Transition to a new technological mode not only leads to the emergence of new opportunities and directions of industrial development, but also causes the need for the formation of new innovative ways of production and commercial activities, the creation of new forms and technologies of enterprise management. The choice of strategy for the development of Russian pharmaceuticals in a new industrialization is complicated by the specifics of the industry. On the one hand, pharmaceutical companies, as a part of the health care system, are uniquely valuable for society and carry an extremely important mission. Innovative medicines developed today, without exaggeration, can change the future of mankind. On the other hand, the production and circulation of pharmaceutical products in Russia is under strict control of the state. The strengthening of state regulation artificially restricts the use of innovative sales technologies and non-traditional sales channels. This leads to a systematic and long-term decline in profitability, which negatively affects the investment attractiveness of the industry.
\end{abstract}

Keywords: pharmaceutical industry, health care, state regulation, $R \& D$ investment

\section{INTRODUCTION}

The pharmaceutical industry plays a crucial role in ensuring the effective functioning of the national health system. It is no coincidence that one of the strategic priorities of the scientific and technological development of Russia is the transition to personalized medicine and innovative health saving technologies, including through the production of modern, highly effective medicines, the use of innovative resource-saving technologies and the introduction of modern quality assurance systems [19].

Numerous scientific researches in the USA, Europe and Asia have been devoted to the study of pharmaceutical development trends and search for new strategies of innovative growth in this industry. This topic is particularly relevant in India, where the pharmaceutical industry is one of the leading innovative sectors of the economy. The works of such scientists as M. Bianchi et. al. [4], D.J. Bower and J.C. Sulej [5], F. Gascon et. al. [8], A. Gautam and X.G. Pan [9], W.F. Jacob and Y.H. Kwak [13], U. Jamwal I. et. al. [14], Khanna [15], M.S. Ku [17] T.R. Madanmohan and R.T. Krishnan [20].

The Russian pharmaceutical industry, on the one hand, is in line with the global trend, making extensive use of innovative formulas and production technologies for medicines. But, on the other hand, artificial restriction of contacts with foreign contractors forces the largest enterprises of the industry to develop local R\&D and localize vertically integrated production $[1,3,7,12,21$, $24]$, which runs counter to the industry trends of recent decades. Under these conditions, the research dedicated to the assessment of key factors and threats that determine the prospects for the development of a large pharmaceutical company operating in the Russian market is of undoubted interest.

\section{METHODS AND MATERIALS}

The development of scenario conditions for the pharmaceutical industry development was based on the theoretical positions of institutional and synergetic theory $[6,16,22,21,27]$, using elements of the theory of analysis of fuzzy sets $[18,23]$.

Applied research was carried out on the basis of materials of Russian pharmaceutical companies whose main activity is the production of pharmaceutical substances, medicines and materials, wholesale of pharmaceutical products, clinical trials and technical analysis of medicines.

Analytical methods and tools of classical strategic management $[2,10,11,26]$ including PEST-analysis, analysis of Porter's competitive forces, SWOT-analysis (primary and elemental) were used to assess the key 
factors of the external environment and develop the company's development strategy.

As sources of additional information in the course of the study were used materials of interviews with representatives of the company, official sites of pharmaceutical companies operating in the Russian market, industry reviews, analysts of consulting companies, statistical data of Russian and international organizations published in the media..

\section{RESULTS}

In the leading countries of the world, the convergence of the scientific-industrial and public sectors at the end of the $\mathrm{XX}$ century led to the emergence of the paradigm of open innovation in the field of pharmaceutical research [4, 25].

The National Institutes of Health (NIH) Roadmap [30] has contributed to the emergence of modern models of intellectual property protection in the field of open innovation, which has led to the creation of a system of sharing of proprietary repositories of biological materials and microsubstations.

Breakthrough discoveries in the field of recombinant DNA and molecular genetics used by pharmaceutical companies for the commercial development of innovative drugs based on synthesized proteins have led to the emergence and rapid development of high-margin biotechnology industry $[4,17,29]$. Active implementation of innovations in pharmaceutics not only creates new industries in the economy, but also serves as a catalyst for the transformation of the pharmaceutical R\&D landscape, redistribution of investment flows between large companies and small start-ups [28].

Tectonic shifts in the pharmaceutical industry have led to the migration of the most creative and talented researchers from large companies to small pharmaceutical start-ups. This process began in the 1990s in San Francisco and Cambridge, where densely concentrated private venture capital was used to finance start-up companies [25]. As a result of the active development of research startups, the situation in which large pharmaceutical companies turn to local developers to obtain rapid access to innovative technologies and drugs has become routine $[8,9]$.

The global trend to increase the transparency of scientific research and the openness of innovative developments runs counter to the trends of pharmaceutical industry development in Russia. National pharmaceutical companies are forced to operate under the conditions of strict state regulation, which significantly limits the opportunities to search for new sales channels and, as a consequence, creates additional barriers for new players to enter the market [19].

There is no reason to expect liberalization of the state policy in the near future. It is obvious that in the conditions of increasing political pressure from outside the strategic task of the state is to ensure the economic security of the country [22], which implies stimulation of the production of own medicinal substances and reduction of dependence of domestic producers of pharmaceutical products on foreign suppliers of raw materials and finished dosage forms.

The pharmaceutical industry is one of the sectors characterized by a stable level of demand for products. Usually, such industries have a high level of competition, but in Russia the policy of strict regulation of commercial activities in the health care sector creates a barrier environment, preventing new companies from entering the market and limiting profitability. Due to these circumstances, potential investors consider investments in the development of the Russian pharmaceutical industry as not promising enough.

Russian companies and generics producers assess the current state of the industry as stable and do not expect a significant deterioration of the situation in the near future. At the same time, foreign producers without localization of production in Russia give a more negative assessment of the prospects for the industry development. In general, the state of the Russian economy is assessed as problematic, especially on the part of those players in the industry who receive the largest share of profits through public procurement of medicines. Also, companies participating in various government programs are concerned about the problem of imperfect legal regulation. They also assess currency risks as high.

Thus, competition in the Russian pharmaceutical market is not characterized by high intensity due to low market growth and significant standardization of products. The behavior of the industry players is also not diverse, many companies' representatives note their readiness to cooperate with competitors for the development of the industry in Russia. At the same time, exit barriers are also quite high due to the specificity of assets.

In the course of the competitive situation analysis the strategic factors of market success were assessed for the four largest suppliers of pharmaceutical products on the Russian insulin market (Table 1).

Company "Sanofi-Aventis" was founded in 2004 after the merger of two large companies: "Sanofi Sintelabo" and "Aventis". This international corporation is presented in 100 countries of the world and possesses a wide portfolio of preparations (more than 60 names) in such branches, as cardiovascular diseases, oncology, diseases of the central nervous system, internal diseases, thrombosis, infringement of a metabolism and a diabetes mellitus. The company's main growth platforms are emerging markets, vaccines, health products and the insulin market. "SanofiAventis focuses on the development of effective, well tolerated medicines: more than 50 innovative medicines are currently in clinical trials.

Novo Nordisk was founded in Denmark by Professor A. Krog in 1923 for the purpose of mass production of insulin. At the moment, the company has 77 branches around the world, and its products are sold in 165 countries. "Novo Nordisk" is engaged in working out and creation of preparations for treatment of a diabetes mellitus, glycemia, obesity, infringements of growth and hemophilia. The company also produces complementary products, such as insulin injectables and needles. The firm 
is focused on strengthening its position in the insulin market and making these products available to patients.

Eli Lilly is a large pharmaceutical corporation founded in 1876. The company's products are sold in 125 countries, its production units are located in 13 different countries, the headquarters of the corporation is in the United States. The company is engaged in search and development of new drug forms, production of drugs using innovative

Table 1 Key factors of successful growth technologies. The unpackaged substances are produced in Ireland, the United Kingdom, the United States and Puerto Rico, and then sent to pharmaceutical factories around the world for packaging. The company's product portfolio includes medicines for diabetes, oncology, mental illness, osteoporosis and erectile dysfunction. The company is more focused on research and development and on finding answers to current questions in the medical field.

\begin{tabular}{|c|c|c|c|c|}
\hline \multirow{2}{*}{ Factor } & \multicolumn{4}{|c|}{ Company } \\
\hline & Sanofi-Aventis & Novo Nordisk & Eli Lilly & Gero-pharm \\
\hline $\begin{array}{l}\text { High degree of integration of research } \\
\text { and production }\end{array}$ & ++ & + & 0 & +++ \\
\hline Closeness to the customer & ++ & ++ & + & ++ \\
\hline $\begin{array}{l}\text { Brand opportunities arising from } \\
\text { government policy }\end{array}$ & + & + & 0 & ++ \\
\hline $\begin{array}{l}\text { Convenient location of production units } \\
\text { (logistics) }\end{array}$ & + & ++ & 0 & ++ \\
\hline Wide range of drugs and substances & ++ & +++ & ++ & + \\
\hline Attractiveness of pricing policy & + & ++ & + & ++ \\
\hline
\end{tabular}

+++- is present to a large extent,

++- is present to a medium extent,

+- is present to a low extent,

$0-$ is not present

The company "Geropharm" appeared in 2001. The production portfolio of the company includes strictly prescription drugs for the treatment of diseases in the field of endocrinology, neurology and ophthalmology, two of which are manufactured using an original patented technology. Since the main income is generated by original prescription drugs, which are sold primarily through retail, the decline in demand for medical drugs in recent years may have a significant impact on the company's profits. However, the negative impact of this trend can be compensated for by additional stimulation of sales of relatively inexpensive generic drugs.

Despite the fact that generics by definition have many analogues, the company has such competitive advantages as the use of high quality raw materials and significant production volumes. In addition, the company is currently the only insulin producer in Russia based on the full cycle principle: from biosynthesis of molecules to delivery of the drug to the end consumer and occupies more than $20 \%$ of the Russian insulin market.

According to the International Diabetes Federation (IDF), more than 415 million people currently have diabetes mellitus, and by 2040 their number will increase to 642 million people, which provides sustainable growth prospects for the market of the company's main product.
Currently, the largest Russian companies are fully supplied with their own raw materials for the production of insulin, producing both finished drugs and substances, that is, active ingredients for the production of drugs, and various recombinant proteins. The maximum possible independence from foreign suppliers is a strategically important key aspect of the industry's activities.

However, full independence from external suppliers of raw materials is not possible. Companies continue to purchase endocrine-enzyme and special raw materials for cattle and pigs. At the same time, the industry as a whole is characterized by the fact that the import of endocrineenzyme raw materials exceeds the volume of collected domestic raw materials by 3.3 times.

The end users of pharmaceutical products are patients with appropriate medical diagnoses. However, the main customer is the state, which through the system of public procurement forms a significant part of the demand for pharmaceuticals to provide budget-funded medical organizations with the necessary medicines. Thus, almost $100 \%$ of the company's profit from the sale of insulin products comes from the state order.

The value proposition of the pharmaceutical company consists, first of all, in the high quality of its products, which is ensured by careful control of all elements of the production chain and significant investments in scientific 
and technical development. The most promising researches are currently conducted in the biotechnological block, including laboratories of genetic engineering, bioorganic chemistry and bioprocesses. Specialists of Russian biotechnological companies take part in all significant scientific events of the industry.

Pharmaceutical products are sold primarily through retail, through contracts with pharmacy chains. In addition, direct sales channels are used to promote new developments: a group of medical representatives directly interact with physicians to inform them about the clinical properties of new drugs and innovative capabilities of the substances offered compared to analogues on the market.

Advertising activities are complicated by specific regulations established for all manufacturers in the industry. Despite this, the leading Russian pharmaceutical companies actively develop PR-projects that contribute to increasing customer loyalty: create thematic pages in social networks, publish articles, participate in various specialized events.

Much attention is paid to the implementation of educational programs and professional competitions that provide the industry with a constant influx of young promising professionals, as well as the systematic organization of professional development programs and exchange of professional experience for employees.

Thus, the strategic advantages of a modern pharmaceutical company are a high degree of integration of scientific and technical research and production, convenient location of production units and brand opportunities provided by the protectionist policy of the state.

Expansion of the product range allows not only to diversify risks, but also to eliminate the lagging behind foreign competitors in the technological characteristics of related products, to strengthen the position of the company's brands in the domestic and global markets.

The increase in the share of pharmacy sales and direct sales reduces the company's dependence on the state as a major customer of some drugs. It is also necessary to pay attention to the use of IT-technologies, which in the near future will play a key role in the potential expansion of sales channels.

In the long term, domestic pharmacists should focus not only on achieving leading positions on the Russian pharmaceutical market, but also on expanding exports and entering new geographical markets with unmet demand.

An important direction of the strategic development of the industry remains the fight against the steady prejudice of consumers with regard to pharmaceutical products of domestic production. To achieve this goal, it is necessary to position Russian pharmaceutical companies in the expert community of the industry, to recognize the company's scientific personnel in the medical community, to widely use new marketing tools, to hold socially significant events and to publish scientific achievements openly.

\section{CONCLUSION}

Based on our research, we concluded that the specific features of the Russian pharmaceutical industry are the need for significant investment, strong government regulation, dependence on foreign suppliers of equipment, relatively constant demand and a low degree of differentiation of the product.

The main competitive advantages of the company under study are valid patents for original drugs and production of insulin on a full cycle basis, which significantly reduces transaction costs.

Recommendations for the company can be presented in the following key areas:

1. Expansion of the portfolio of drugs and complementary products.

2. Search for new sales channels and geographic expansion.

3. Elimination of negative connotations in relation to the domestic drug manufacturer.

\section{REFERENCES}

[1] R.A. Kutuev, R.H. Dadashev, D.Z. Elimkhanov, Surface tension of melts of multi-component systems, Izv. Kabardino-Balkarian State Univer. 1(4) (2011) 8-1.

[2] R.A. Kutuev, Surface tension and adsorption in indium-olovine-lead-bismuth melts, Materials of the All-Russian scientific conference of students, postgraduates and young scientists, Perspective2002, vol. 2, KBGU, Nalchik, 2002, pp. 90-94. 